\title{
IN VITRO STUDY ON ANTIOXIDANT ACTIVITY OF DIFFERENT EXTRACTS OF ALLIUM SATIVUM.L (BULB) AND THE DIGESTIBILITY
}

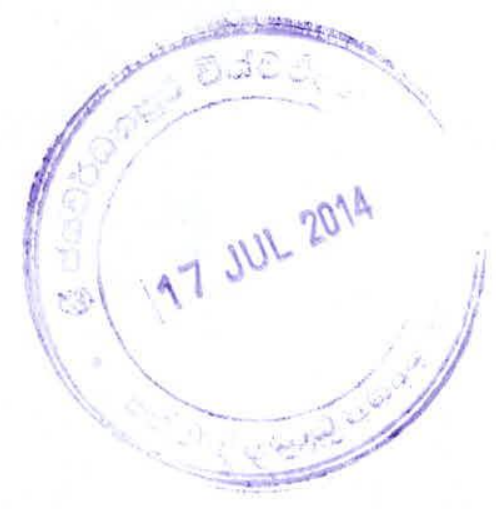

By

Asana Lebbe Muhammed Ihsan

This Thesis submitted in partial fulfillment of the requirements for the Degree of Masters of Food Science and Technology,

Department of Food Science and Technology,

Faculty of Applied Science,

University of Sri Jayewardenepura, Sri Lanka 


\section{DECLARATION}

The work described in this thesis was carried by me, under the supervision of Dr. (Mr.) R. A. U.J. Marapana and the report on this thesis has not been submitted in whole or in part of any University or any other institution for another Degree/ Diploma.

$10-01-2014 \ldots \ldots$

Date

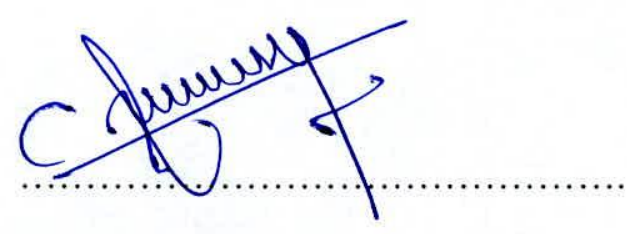

A.L.M.Ihsan 
"I certify that the above statement made by the candidate is true and that this thesis is suitable for submission to the university for the purpose of evaluation"

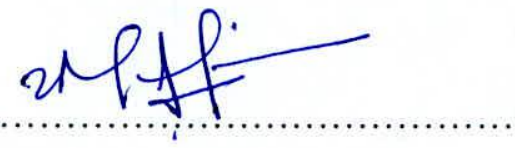

Dr. (Mr.) Dr. R. A. U.J. Marapana

Date

Department of Food Science and Technology,

Faculty of Applied Sciences,

University of Sri Jayewardenepura,

Sri Lanka. 
Affectionately dedicated to my father, mother and ever loving teachers 


\section{TABLE OF CONTENT}

\section{Page}

LIST OF CONTENT

LLST OF TABLES $\quad$ V

LLST OF FIGURES $\quad$ V

ACKNOLAWDGEMENT $\quad$ VI

ABSTRACT VII

CHAPTER 1: INTRODUCTION 1

CHAPTER -2: LITERATURE REVIEW

2.1 Antioxidants 4

2.1.1 Enzymatic antioxidants 4

2.1.2 Non-enzymatic antioxidants 5

$\begin{array}{ll}\text { 2.1.3 Thiol antioxidants } & 6\end{array}$

2.1.4 Co-factors 9

$\begin{array}{ll}2.2 \text { Free radicals } & 12\end{array}$

$\begin{array}{ll}2.3 \text { Digestibility } & 19\end{array}$

2.4 Taxonomy of Garlic (Allium sativum. L) 20

2.4.1 Botanical description of Garlic 20

$\begin{array}{ll}\text { 2.4.2 General appearance } & 21\end{array}$

2.4.3 Organoleptic properties $\quad 21$

$\begin{array}{ll}\text { 2.4.4 Microscopic characteristics } & 21\end{array}$

2.4.5 Powdered plant material 22 
2.4.9.2.6 Atherosclerosis prevention $\quad 35$

2.4.9.2.7 High blood pressure/ Hypertension Effects 35

2.4.9.2.8 Blood glucose effects

2.4.9.2.9 Anti-Inflammatory Effects 36

$\begin{array}{ll}\text { 2.4.9.2.10 Immunology } & 37\end{array}$

$\begin{array}{ll}\text { 2.4.9.2.11 Dosage forms } & 37\end{array}$

$\begin{array}{ll}\text { 2.4.9.2.12 Contraindications } & 38\end{array}$

$\begin{array}{ll}\text { 2.4.9.2.13 Side Effects } & 38\end{array}$

2.4.9.2.14 Interactions with other drugs $\quad 39$

2.4.9.2.15 Garlic Dosing

\section{CHAPTER - 3: METHODOLOGY}


3.1.2 Preparation of the garlic powder $\quad 40$

3.1.3 Powder material $\quad 41$

3.1.4 Packaging of oven dried garlic powder $\quad 41$

3.2 Chemical Analysis $\quad 41$

3.2.1 Determination of moisture (Oven drying method) 41

3.2.2 Determination of Total Ash $\quad 42$

3.2.3 Determination of Crude fiber 43

3.2.4 Determination of Crude Protein (Kjeldhal method) 45

3.2.5 Determination of Free Fat 47

3.2.6 Analysis of Vitamin C content in garlic powder 48

3.2.6.1 Standardization of indophenols dye solution $\quad 48$

3.2.6.2 Determination of ascorbic acid of garlic powder 48

3.3 Qualitative Phytochemical analysis of Garlic 49

$\begin{array}{ll}\text { 3.3.1 Test for proteins (Millon's test) } & 49\end{array}$

3.3.2 Test for reducing sugars (Fehling's test) 49

3.3.3 Test for carbohydrates (Benedict's test) $\quad 49$

3.3.4 Test for phenols and tannins $\quad 49$

3.3.5 Test for flavonoids (Alkaline reagent test) $\quad 49$

$\begin{array}{ll}\text { 3.3.6 Test for steroid } & 50\end{array}$

$\begin{array}{ll}3.3 .7 \text { Test for alkaloids } & 50\end{array}$

$\begin{array}{lr}\text { 3.3.8 Fatty acids } & 50\end{array}$

3.4 Microbiological Analysis $\quad 51$ 
3.4.2 Most Probable Number (MPN) of coliform bacteria 52

3.4.2.1Composition of macConkey broth $\quad 52$

3.4.2.2Composition of BGLB 53

3.4.2.3 EMB agar $\quad 53$

3.4.2.4 Confirmation test 54

3.4.2.5 Completed test $\quad 54$

3.4.3 Detection of total Yeast and Molds count 54

3.5 Determination of antioxidant activity of different garlic extracts $\quad 54$

3.5.1 Preparation of Water extracts and Ethanol extracts 54

3.5.2 Determination of free radical scavenging activity by DPPH assay 55

3.6 Determination of digestibility of samples of high antioxidant activities $\quad 55$

\section{CHAPTER -4: RESULTS AND DISCUSSION}

4.1. Results and discussion of chemical analysis

4.2 Results and discussion of phytochemical analysis 


\section{LIST OF TABLE}

2.1 Enzymatic antioxidants

2.2 Digestive Enzymes of the Pancreas

2.3 Chemical Constituents of Garlic

2.4 Nutritional value of Allium sativum. $L$

4.1 Proximate composition of dried garlic powder 57

4.2 Dietary Reference Intakes (DRI) for Fiber 60

4.3 Phytochemical Observation of Allium. sativum Extracts 64

4.4 Phytochemical Constituents of Allium sativum Extracts

4.5 Microbiological analysis of garlic powder

4.6 DPPH antioxidant activity of Allium sativum extracts

\section{LIST OF FIGURS}

2.1 Sulfur compounds of garlic powder

3.1 Flow diagram for the preparation of garlic powder 


\section{ACKNOLEGMENT}

I express my profound thanks to my honorable supervisor Dr. R. A. U. M. Marapana, senior lecturer, Department of Food Science and Technology, University of Sri Jayewardenepura, Nugegoda, for his individual guidance, support and encouragement thought this research study. His constructive criticisms and helpful suggestions have been greatly helpful in the preparation of this research paper. And I also grateful to all academic and non-academic staff including Assistant Coordinator/MSc programme Mrs. Rupika Perera of the Department of Food Science and Technology, University of Sri Jayewardenepura, their invaluable help and guidance. I must thank to the colleagues of my batch, other participant and other personals whom were considered for the purpose of this research. Without their co-operation, this research would never have reached this stage.

Meantime, the special thanks go to my beloved elder brother Mr.A.L.M.Saleeth for his unforgettable helps, encouragement support and dedication of several hours of precious his time for my successful. 


\section{ABSTRACT}

Spice garlic is indispensable for the preparation of our daily food and is reported to possess compounds, which have varied beneficial biological effects. Antioxidants are compounds which act within the human body to stop oxidative damage to cell walls. This study evaluated the antioxidant activity in different extracts of garlic by 2, 2'-Diphenyl-1picrylhydrazyl (DPPH) Radical Scavenging Method. This study mainly focuses on the areas such as free radicals scavenging activity, the digestibility and Phytochemical, Chemical, and Microbiological analysis of Allium sativum L.

The antioxidant activities when compared among different types of garlic extracts, the potency of these extracts was found to be in the order of (Butylated Hydroxyl Toluene) BHT $>$ Aqueous extract of garlic powder $($ S2) $>$ Ethanol extract of garlic powder $($ S4) $>$ Aqueous extract of fresh garlic $(\mathrm{S} 3)>$ Ethanol extract of fresh garlic (S4). The quantitative results of DPPH activity was $19.80 \mu \mathrm{g} / \mathrm{mL}, 270.53 \mu \mathrm{g} / \mathrm{mL}, 286.32 \mu \mathrm{g} / \mathrm{mL}$, $659.41 \mu \mathrm{g} / \mathrm{mL}$ and $701.58 \mu \mathrm{g} / \mathrm{mL}$ respectively. The study indicates that the different types of extracts of garlic have antioxidant activities in different levels. The overall digestibility of aqueous and ethanol garlic powder extracts (S2 and S4) were in the range of 62.67$77.47 \%$ and the highest digestibility was observed in S2.The proximate analysis of the garlic powder gave the following results in percentage as Moisture 4.57, Total ash 4.66, Crude fiber 2.84, Free fat0.77, Crude protein 15.43 and Vitamin C10.04 mg. The microbiological analysis of garlic powder gave the results as Total Plate Count $3 \times 10^{5}$ CFU/gram, Total Coliform Count $2 \mathrm{MPN} /$ gram and Yeast and Mold count $3 \times 10^{2}$ CFU/gram. Both the aqueous and ethanol extracts were found to contain carbohydrates, reducing sugars, lipids, flavonoids, ketones, alkaloids, steroids and triterpenes. In the acetone extract alkaloids, steroids and triterpenes were absent. Tannins and polyphenols were not detected in any of the Allium sativum extracts.

So the different extracts of fresh and powdered garlic having antioxidant activity and the digestibility in different levels. The proximate, phytochemical and microbiological analyses are confirmed that the garlic can play an important role in human being as a functional food.

Keywords: Garlic, Antioxidant Activity, Digestibility, DPPH activity. 


\section{CHAPTER -1}

\section{INTRODUCTION}

Antioxidants are compounds which act within the human body to stop oxidative damage to cell walls. These life-sustaining molecules occur naturally in the human diet and may help to prevent and treat several common conditions.

Number of chemical constituents of plants including polyphenols, flavanoides, saponins, vitamins and mineral have been proven to possess antioxidant properties. Vitamin $\mathrm{A}$ as beta-carotene, vitamin C, vitamin E, Selenium and Copper are some of them.

Beta Carotene also known as pro-vitamin A, beta-carotene possesses powerful antioxidant properties. Beta-carotene acts as a natural precursor to vitamin A, or retinol, which is essential for eye health and overall wellbeing. Vitamin $\mathrm{C}$ best known for its popular (albeit controversial) use as an immune stimulant, vitamin $\mathrm{C}$ possesses powerful antioxidant properties. This micronutrient, also known as ascorbic acid, appears naturally in varieties of vegetables and fruits. Many processed foods and drinks are also fortified to contain extra vitamin $\mathrm{C}$, which can protect food from oxidative damage and discoloration.

Vitamin $\mathrm{E}$ is perhaps the most critical vitamin that acts as an antioxidant. This healthy, fat soluble vitamin occurs naturally in number of food stuffs. The most common form of vitamin E used in food is D-alpha tocopopherol, which is the subject of ongoing scientific investigation regarding its benefits and risks.

Although selenium is frequently classified as a vitamin, it is in fact a trace mineral. This antioxidant mineral may help to prevent the forms of oxidative damage associated with cancer, so health care providers frequently recommend it as an alternative therapy or preventative remedy for the disease. According to the National Institutes of Health, preliminary but inconclusive evidence supports the use of selenium supplements for preventing prostate, gastrointestinal, gynecological, lung, colorectal, and esophageal cancers. Thus disturbed balance between radical formation and radical neutralization leads to oxidative damage of cell components such as proteins, lipids and nucleic acids (Naziro., 2005). 
Cardiovascular diseases are the most common cause of morbidity and mortality worldwide. In western countries they account for almost 17 million deaths (Smith et al., 2004). In developing countries their prevalence is becoming important towards urbanization, industrialization and changing life styles (Yusuf et al., 2001). According to the estimate of the World Health Organization (WHO), approximately 80 percent of the people in developing countries rely directly on traditional medicines for the primary health care, of which a major portion involves the use of plant extracts or active principles originating from parts of plants (Farnswoth et al., 1985).

Garlic (Allium sativum L.) is well known for its medicinal benefits, especially in helping to prevent cancer and cardiovascular diseases. Alliins (S-alk(en)yl-l-cysteine sulfoxides) are sources of major active compounds in allium plants. Allicin (diallythiosulfinate) is the main biologically active component of freshly crushed garlic cloves.

Antioxidant compounds in food are found to have a health-protecting factor. Primary sources of naturally occurring antioxidants are whole grains, fruits and vegetables. Garlic has been used in world cuisines as well as in herbal medicine for thousands of years and, at times, has been claimed to help prevent everything from high cholesterol to cancer. No clinical trials have been performed with allicin and it was never developed into a drug or commercial product due to its instability, its inability to be absorbed and its offensive odour.

It is produced by the interaction of the non-protein amino acid alliin with the enzyme alliinase. All of the background research involving allicin has been done on either garlic powder from different manufacturers (Lawson et.al., 1991) or processing the garlic cloves through many different chemicals in order to obtain allicin.

The chemopreventive effect of S-allylcysteine (SAC), a water-soluble garlic constituent is playing an important role in gastric carcinogenesis. The modulatory effects of garlic on hepatic and blood oxidant-antioxidant status may play a key role in preventing cancer development at extrahepatic sites. The antiatherogenic effects of egg yolk-enriched garlic powder, which has been used as a traditional health-promoting food in southern Japan since ancient times, on LDL oxidation and oxidant stress induced cell injury models were reported. Trace elements such as Selenium and Copper are very important components of garlic. Selenium in garlic significantly increases the ability of garlic to prevent and inhibit cancer. The major selenocompounds found in selenized garlic are Se- 
methylselenocysteine and gamma-glutamyl-Se-methylselenocysteine (Auger et al., 2004; Ogra and Suzuki., 2005).

The number of modern lipid lowering drugs consist side effects (Stanch and Sima., 2001) and Limitations of the use of synthetic statins are pregnancy and lactations, etc (James., 2004). The recent scientific reseeach reveals the garlic is very effective in hypercholesterolaemia and atherosclerosis (Paranjpe., 2012). Also Plant protein appears to lower cholesterol level (James., 2004).

Digestibility is a measure of the efficiency of digestion and absorption of various nutrients present in a food. Not all the nutrients present in food are available to the human for metabolism. Digestibility is an important consideration in the formulation of prepared human foods and dietary supplements, since a food with an ideal nutrient profile and excellent palatability is of no nutritional benefit if it cannot be broken down and assimilated by the human. So the nutrients contain mainly such as proteins, carbohydrates and lipid of foods should be in high digestibility, then it can give good nutritional and medicinal benefits to the humans.

The main Objective of this study was to assess the free radicals scavenging activity of the different extracts of Allium sativum by DPPH assay and find the extract type with high antioxidant activity and the digestibility. The other specific objectives were to analyze the Phytochemical, Chemical and Microbiological part of the garlic powder and to promote community awareness on Allium sativum as a functional food. 


\section{CHAPTER - 2}

\section{LITERATURE REVIEW}

\subsection{Antioxidants}

The term "antioxidant" refers to any molecule capable of stabilizing or deactivating free radicals before they attack cells. Humans have evolved highly complex antioxidant systems (enzymic and nonenzymic), which work synergistically, and in combination with each other to protect the cells and organ systems of the body against free radical damage. The antioxidants can be endogenous or obtained exogenously as a part of a diet or as dietary supplements respectively. Some dietary compounds that do not neutralize free radicals, but enhance endogenous activity may also be classified as antioxidants.

An ideal antioxidant should be readily absorbed and quench free radicals, and chelate redox metals at physiologically relevant levels. It should also work in both aqueous and/or membrane domains and effect gene expression in a positive way. Endogenous antioxidants play a crucial role in maintaining optimal cellular functions and thus systemic health and well-being. However, under conditions, which promote oxidative stress, endogenous antioxidants may not be sufficient and dietary antioxidants may be required to maintain optimal cellular functions.

The most efficient enzymatic antioxidants involve glutathione peroxidase, catalase and superoxide dismutase (Mates et al., 1999). Nonenzymatic antioxidants include Vitamin E and C, thiol antioxidants (glutathione, thioredoxin and lipoic acid), melatonin, carotenoids, natural flavonoids, and other compounds (McCall and Frei., 1999). Some antioxidants can interact with other antioxidants regenerating their original properties; this mechanism is often referred to as the "antioxidant network" (Sies et al., 2005).

\subsubsection{Enzymatic antioxidants}

This Enzymatic antioxidants consists number enzymes such as Glutathione peroxidase, Catalase, Superoxide dismutase. 